\title{
o que podemos no encontro com a infância? um convite a um olhar heterotópico
}

\author{
letícia de lima borges ${ }^{1}$ \\ universidade federal de santa maria, santa maria, rio grande do sul, brasil \\ orcid id: https://orcid.org/0000-0003-2531-667x \\ eliana da costa pereira de menezes 2 \\ universidade federal de santa maria, santa maria, rio grande do sul, brasil \\ orcid id: https:/ / orcid.org/0000-0002-5908-0039
}

\section{resumo}

Este artigo objetiva propor um convite a olhar a infância que estamos produzindo a partir das práticas da Educação Especial, na articulação com as práticas da Educação Infantil, problematizando as tramas discursivas que se constituem nessa articulação, a partir dos olhares operados sobre a infância por professoras de Educação Especial de escolas de Educação Infantil da Rede Municipal de Ensino. Tais discussões justificam-se a partir do desassossego de pensarmos como estamos produzindo a infância, a partir da política de ampliação da obrigatoriedade de frequência para os quatro anos de idade. O exercício analítico, inspirado na análise de discurso proposta por Michel Foucault, possibilitou-nos tensionar a produção de sujeitos, verdades e realidades nas "confissões" das professoras entrevistadas, em que destacamos dois modos de pensar e produzir a infância: a infância capturada, produzida via operacionalização das práticas de normalização pelas ações da Educação Especial, determinadas pela vontade de saber e vontade de poder sobre a infância; a infância como heterotopia, produzida como movimento potente de resistência e desnaturalização das práticas normalizadoras - uma infância pensada a partir de outros lugares, como um vir a ser infinito, múltiplo, não-nomeável, sempre indeterminado, como um convite ao pensamento: o que podemos no encontro com a(s) infância(s)?

palavras-chave: discurso; infância; educação especial; heterotopia.

\section{what can we do in the encounter with childhood? an invitation to a heterotopic look}

\section{abstract}

This paper aims to propose an invitation to look at the kind of childhood we have been constructing from the practices of Special Education, in articulation with the practices of Early Childhood Education. It problematizes the discursive webs formed in this articulation, considering the way that Special Education teachers working with Early Childhood in public schools regard childhood. Such discussions have derived from the uneasiness of thinking about how we have been producing childhood, given the policy of expanding mandatory attendance to four-year-old children. The analytical exercise, inspired by the discourse analysis proposed by Michel Foucault, has enabled us to question the production of subjects, truths and realities in the "confessions" of the interviewed teachers, in which we have identified two ways of thinking about and producing childhood: captured childhood, which is produced through the operationalization of normalization practices by Special Education, determined by the will to knowledge and the will to power

\footnotetext{
${ }^{1}$ Email: leti_lb@hotmail.com

${ }^{2}$ Email: eliana.menezes@ufsm.br
} 
o que podemos no encontro com a infância? um convite a um olhar heterotópico

over childhood; and childhood as heterotopy, produced as a powerful movement of resistance and denaturalization of normalizing practices - childhood regarded from other places, as an infinite, multiple, non-nameable, ever undetermined becoming, as an invitation to thought: what can we do in the encounter with childhood(s)?

keywords: discourse; childhood; special education; heterotopy.

\section{¿qué podemos en el encuentro con la infancia? una invitación a una mirada heterotópica}

\section{resumen}

Este artículo tiene por objetivo proponer una invitación a observar la infancia que estamos produciendo a partir de las prácticas de la Educación Especial, en la articulación con las prácticas de la Educación Infantil, problematizando las tramas discursivas que se constituyen en esa articulación, a partir de las observaciones operadas sobre la infancia por profesoras de Educación Especial de escuelas de Educación Infantil de la Red Municipal de Enseñanza. Tales discusiones se justifican a partir del desasosiego de pensar cómo estamos produciendo la infancia, a partir de la política de ampliación de la asistencia obligatoria para los cuatro años de edad. El ejercicio analítico, inspirado en el análisis del discurso propuesto por Michael Foucault, nos posibilitó tensionar la producción de sujetos, verdades y realidades en las "confesiones" de las profesoras entrevistadas, en las que destacamos dos modos de pensar y producir la infancia: la infancia capturada, producida vía operacionalización de las prácticas de normalización por las acciones de Educación Especial, determinadas por la voluntad de saber y la voluntad de poder sobre la infancia; la infancia como heterotopía, producida como movimiento potente de resistencia y desnaturalización de las prácticas normalizadoras - una infancia pensada a partir de otros lugares, como un venir a ser infinito, múltiple, innombrable, siempre indeterminado, como una invitación al pensamiento: ¿qué podemos en el encuentro con la(s) infancia(s)?

palabras clave: discurso; infância; educación especial; heterotopía. 


\section{o que podemos no encontro com a infância? um convite a um olhar heterotópico}

\section{1. para iniciar a conversa...}

A escrita deste artigo resulta de um recorte da pesquisa de dissertação de mestrado desenvolvida no Programa de Pós-Graduação em Educação na Universidade Federal de Santa Maria, intitulada: "Modos outros de pensar a infância: um convite ao pensamento a partir da Educação Especial”. Neste estudo, partimos do problema de compreender quais foram os efeitos da articulação das práticas da Educação Especial com a Educação Infantil na produção da infância. Nosso propósito foi identificar e compreender que infância é essa que vinha sendo produzida na escola, a partir das discursividades produzidas pelas professoras de Educação Especial, quando convidadas a pensar a produção da infância e de suas práticas naquele cenário.

Tais discussões justificam-se a partir do desassossego de pensarmos como estamos produzindo a infância, desde a política de ampliação da obrigatoriedade de frequência para os quatro anos de idade 3 , problematizando as práticas da Educação Especial como estratégias de governamento da infância quando articulada ao contexto da Educação Infantil. Essa problematização impulsionou-nos a assumir os riscos de colocar sob suspeita os modos de produção da infância operados pela Educação Especial na escola, para movimentarmo-nos na direção de modos outros de pensar a infância, tensionando os modos produzidos historicamente, que a percebem e a produzem como etapa do desenvolvimento evolutiva, linear e cronológica universal.

A partir desse objetivo, organizamos as tramas que enredaram essa problematização, na medida em que a materialidade da pesquisa se mostrou potente para pensar os modos de produção da infância engendrados pela articulação daquelas práticas no contexto em que a inclusão opera como imperativo.

\footnotetext{
${ }^{3}$ Lei 12.796/2013, que modifica o artigo $4^{\circ}$ da Lei de Diretrizes e Bases (BRASIL,1996) e amplia a obrigatoriedade de frequência escolar para os quatro anos de idade.
} 
o que podemos no encontro com a infância? um convite a um olhar heterotópico

Ao mesmo tempo, provocou modos outros de pensar a infância, diferentemente do que se vinha pensando e produzindo.

Assim, com Walter Kohan (2005, p. 252), percebemos a infância como a "infinita possibilidade de quebrar a inércia repetitiva do mesmo", não nomeável, sempre indeterminada e imprevisível, que tanto perturba a noção utópica e linear de desenvolvimento. Os movimentos que nos fizeram pensar a infância desse modo foram desdobrados a partir dos diferentes elementos que emergiram durante a realização da pesquisa, da qual neste artigo apresentamos um breve recorte: a captura da infância por meio da naturalização das práticas de normalização e as possibilidades outras de pensar a infância a partir do mesmo lugar que produz a norma.

\title{
2. localizações do percurso teórico-metodológico
}

\begin{abstract}
Pensar a infância, problematizando-a como uma invenção, permite perceber sua construção histórica como categoria das ciências do homem e a forma como ela é engendrada no contexto social moderno. Nesse sentido, pensá-la com Foucault possibilita ver, desde essa perspectiva administrativa, o que se está fazendo da infância e com a infância em nosso tempo. (Resende, 2015, p. 7).
\end{abstract}

Ainda que Michel Foucault não tenha se ocupado especificamente em produzir teorizações sobre a infância e a educação, suas formulações conceituais viabilizam a desnaturalização de definições estáticas, universais e essencialistas que produzem um modelo de ser articulado a um modelo de desenvolvimento humano evolutivo determinante e único, a priori. Permitem, também, perceber os sujeitos como produto das relações de poder e saber que se estabelecem nos diversos contextos sociais onde são inseridos, bem como nas relações consigo mesmos.

Porém, não se trata de pensarmos uma infância ou a infância como uma verdade. Trata-se de mostrar como se constrói e fortalece uma rede de discursos sobre a infância que têm oportunizado instituir certo tipo de sujeito infantil e também subjetivado a todos e cada um a acreditar nesse modo de ser único e idealizado. Por isso, assumindo a perspectiva pós-estruturalista, pensamos uma 
infância com outras lentes, problematizando-a como uma invenção histórica, como uma produção daquilo que o discurso nomeia para poder controlar, regular e corrigir, por uma questão de seguridade.

Assim, percebemos que a infância não esteve desde sempre aí e que o modo como se constituiu não determina um modo de ser universal, havendo uma multiplicidade de formas de/em pensá-la. Foi olhando para a produtividade dos discursos que nos convencem e nos subjetivam a uma verdade sobre a infância, que pensamos a infância como descontinuidade, ao invés de a pensarmos como etapa cronológica do desenvolvimento humano que enquadra habilidades e aprendizagens em um tempo determinado, fragmentado e contínuo-

A infância como encontro com o desconhecido, com o imprevisível, "como busca de outros territórios, como história sempre nascente, como devir, como possibilidade de pensar o que não se pensa e de ser o que não se é, de estar em outro mundo daquele no qual não se está" (Kohan, 2005, p. 248). A infância como o vir a ser infinito, não nomeável, sempre indeterminado, que tanto perturba a noção linear e progressista de desenvolvimento. Uma oportunidade de romper com a continuidade utópica que nos constitui como sujeitos modernos, de pensar infâncias outras $^{4}$ a partir desse lugar outro que aposta "na singularidade do acontecimento" (Kohan, 2005, p. 253).

Esses deslocamentos favorecem encontros e entendimentos outros para (re)significar e pensar diferentemente de como vinha se pensando a infância. Foucault (2013) chama de "função inquietante das heterotopias versus a função 'acomodante' das utopias". Isto é, "se as últimas mostram as possibilidades outras da linguagem, de modo quimérico, e fazem sonhar com lugares inexistentes, as heterotopias fazem totalmente o contrário. Elas explicitam as diferenças, ao manifestá-las, na mesma linguagem" (Gallo, 2015, p. 437). É destes "lugares outros" que buscamos problematizar a infância como efeito da linguagem, como heterotopia, fazendo o convite ao pensamento.

\footnotetext{
${ }^{4}$ Fazemos a provocação durante a escrita do texto, deslocando o pronome "outro/a" para depois dos substantivos, porque entendemos que existem múltiplas possibilidades de ser, que sem dúvida inquietam e desacomodam a linguagem.
} 
o que podemos no encontro com a infância? um convite a um olhar heterotópico

Defendemos a infância como heterotopia e convidamos a pensá-la, não como invenção de outra infância, mas como uma possibilidade de modos outros de ver e ser infância, "produzindo diferenças nela e com ela, fazendo-a proliferar" (Gallo, 2015, p. 437). Uma maneira outra de pensar a infância que se desgarra do modo ordeiro centrado em um ideal evolutivo a ser alcançado.

Por isso, tomando a noção de infância como heterotopia, olhamos para os efeitos da articulação das práticas da Educação Especial com a Educação Infantil produzidas pelas discursividades das professoras da Educação Especial quando convidadas a pensar a produção de suas práticas, a partir da política de ampliação da obrigatoriedade de frequência na Educação Infantil que antecipa a entrada das crianças no contexto escolar para os quatro anos de idade.

Nesse exercício de provocar algumas torções no pensamento para pensar a infância de outros modos, tomamos como ferramenta conceitual a noção de discurso, teorizada por Michel Foucault. A partir do autor, entendemos o discurso como uma prática produtora de sujeitos, realidades e, portanto, verdades. Por isso, para percebermos "no nível de existências das palavras, das coisas ditas" (Fischer, 2012, p. 74), é "preciso trabalhar arduamente com o próprio discurso, deixando-o aparecer na complexidade que lhe é peculiar" (Fischer, 2012, p. 74).

Trata-se de entender que a linguagem não simplesmente expressa um pensamento, não simplesmente interpreta contextos e realidades, mas produz, constrói e inventa sujeitos, modos de ser e a própria realidade. Ainda, a linguagem desconstrói a ideia de lugar privilegiado e universal desse discurso reconhecido pelas "sociedades de discurso", cuja função é conservar ou produzir discursos para fazê-los circular em determinados espaços, distribuindo-os segundo regras restritas (Foucault, 2013).

Por isso, olhamos com suspeita para como a Educação Especial articula suas práticas com a Educação Infantil e tem pensado a infância nesse contexto, pois esse imbricamento permite perceber que há, nessas relações, entre os campos do saber, um conjunto de discursos que, na tentativa de sobreposição de uma verdade sobre outra, produz significados para um modo de ser sujeito que "constituem formas regulares de incluir, readaptar e normalizar" (Lunardi-Lazzarin e Menezes, 2015, p. 
207). Discursos que têm como possível efeito mais governamento de uns e de outros e "não podem ser dissociados dessa prática de um ritual que determina para os sujeitos que falam, ao mesmo tempo, propriedades singulares e papéis preestabelecidos" (Foucault, 2013, p. 37).

Esse ritual da palavra imbricado nas/pelas práticas parece-nos servir tanto para localizar e classificar o/a deficiente, quanto para acionar o autoinvestimento no outro que não é deficiente. Logo, quanto mais prevenção, mais incidência sobre o corpo, mais controle, mais regulação; portanto, mais governamento ao antecipar a captura das infâncias. Ou seja, quanto mais cedo a infância é exposta a ações de prevenção, controle, regulação e correção, mais chances de convencer a todos e cada um da necessidade desta antecipação são estabelecidas, por uma questão de seguridade e controle. A antecipação emerge, portanto, como garantia

[...] da organização e da oferta de um espaço educativo em que as melhores qualidades do gênero humano fossem favorecidas e levadas a desabrochar, representando um futuro para a humanidade mais fraterno, solidário, tendente a garantir a equidade nas relações de poder e a distribuição do saber etc. etc. etc. A escola infantil e as propostas pedagógicas nela desenvolvidas teriam, nesta perspectiva, um papel preponderante na superação da ignorância e da opressão que caracterizariam o nosso sistema social e constituiriam, por certo, um fator significativo na consecução da equidade. (Bujes, 2007, p. 13).

No cruzamento entre as práticas, Educação Especial parece-nos configurarse como um elemento da rede discursiva constituída por diferentes campos do saber, como a psicologia, a psiquiatria, a medicina e a pedagogia, que também ritualiza um discurso sobre os modos de ser dentro da escola. Discursos que colocam em funcionamento práticas "tanto para disciplinar, corrigir e reabilitar os indivíduos deficientes" (Lunardi-Lazzarin e Menezes, 2015, p. 207), quanto para entendê-los e produzi-los como sujeitos também envolvidos e interessados em práticas que lhes facultem destituir-se de comportamentos indesejáveis. Essas práticas fortalecem as verdades produzidas por esses campos do saber no contexto educacional e contribuem para a "organização e a oferta de um espaço educativo em que as melhores qualidades do gênero humano fossem favorecidas e levadas a desabrochar" (Bujes, 2007, p. 15). 
o que podemos no encontro com a infância? um convite a um olhar heterotópico

Mas que verdades são essas? Como a articulação das práticas da Educação Especial e da Educação Infantil produzem verdades sobre os sujeitos infantis? Que ações e discursos são provenientes para a produção da infância deficiente? Por que governar a infância? Com e a partir dessas inquietações e com o objetivo de problematizar os efeitos da articulação das práticas da Educação Especial com a Educação Infantil na produção da infância, buscamos perceber as tensões, rupturas, torções e desvios que, sobre solos utópicos, têm assentado um cenário educacional naturalizado, que produz e nomeia um tipo ideal de infância.

Para localizarmos o cenário educacional lócus da pesquisa, fizemos um levantamento, junto à Secretaria Municipal de Educação (SMED) de Santa Maria/RS, de quantas escolas municipais de Educação Infantil (EMEI) estavam registradas no ano de 2018. A rede de ensino contemplava um total de 75 escolas, distribuídas nas diferentes regiões do município. Dentre elas: uma Escola Municipal de Artes Eduardo Trevisan (EMAET); uma Escola Municipal de Aprendizagem Industrial (EMAI); 20 Escolas Municipais de Educação Infantil (EMEI) e 54 Escolas Municipais de Ensino Fundamental (EMEF).

Do montante de 20 escolas, selecionamos as Escolas Municipais de Educação Infantil (EMEI) que sinalizaram atender aos seguintes critérios: ter matriculadas crianças consideradas público-alvo ${ }^{5}$ da Educação Especial; possuir um/a professor/a de Educação Especial ${ }^{6}$ articulando suas práticas com a Educação Infantil; e oferecer Atendimento Educacional Individualizado (AEE). Nesse levantamento, destacamos 10 escolas, que serviram como lócus para o desenvolvimento das problematizações deste estudo, e as práticas e discursos das Educadoras Especiais que nelas atuavam, o objeto de investigação.

Após essa escolha das escolas, convidamos as nove professoras ${ }^{7}$ de Educação Especial atuantes nestes 10 contextos educacionais de Educação Infantil sinalizados.

\footnotetext{
${ }^{5}$ A Resolução CNE/CEB, no 4 de 2009 define o público-alvo da Educação Especial como: alunos/as com deficiência, transtornos globais do desenvolvimento e altas habilidades/superdotação (Brasil, 2009, p. 1).

${ }^{6}$ Apenas uma professora não tinha formação de Licenciatura em Educação Especial. Era Licenciada em outra área do conhecimento, com a complementação da Especialização em Atendimento Educacional Especializado, oferecida pela UFSM.

${ }^{7}$ Para preservar as identidades das professoras e das escolas, e identificar os fragmentos analíticos, nomeamos as EMEIS com a letra "E"; para identificar as professoras Educadoras Especiais, usamos
} 
A partir de um roteiro de perguntas, guiamos nossa conversa de modo mais livre, permitindo capturar as confissões à medida que convidávamos as professoras a pensar sobre a inserção e prática da Educação Especial no contexto da Educação Infantil. As perguntas do roteiro direcionavam-nos para compreender como acontecia a organização de suas práticas na escola a partir dessa interlocução e se ramificou para os demais questionamentos que foram emergindo ao longo das conversas. Buscamos entender como era sinalizada a necessidade de atendimentos educacionais especializados (AEE) para as crianças e quais eram, especificamente, os aspectos considerados para que as crianças fossem encaminhadas para o AEE e/ ou necessitassem de um olhar mais atento da Educadora Especial.

Com base nisso, procuramos compreender como aconteciam os encaminhamentos e se as Educadoras Especiais percebiam que o atendimento estava auxiliando no desenvolvimento das crianças, relatando os aspectos que percebiam como relevantes. A indicação desses aspectos desencadeou discussões sobre a organização dos planejamentos para os atendimentos no AEE e na sala regular, de forma a compreender se e quando, naqueles contextos, havia coletividade nos modos de pensar sobre as práticas empreendidas e seus efeitos sobre os sujeitos. Com uma noção geral da organização das práticas da Educação Especial, outros elementos foram emergindo dos relatos sobre os encaminhamentos das crianças, como os atravessamentos com profissionais de outras áreas do saber.

A partir das conversas, gravadas e transcritas, visualizamos que a materialidade possibilitaria trilhar diferentes caminhos analíticos para pensar a produção da infância no contexto da articulação das práticas da Educação Especial com a Educação Infantil. Foi a partir da tríade escola, deficiência e governo que organizamos e estruturamos a analítica das problematizações, pois as confissões ${ }^{8}$ nos levaram a perceber que é a partir dessa tríade e de suas ramificações que os

\footnotetext{
as letras "EE", seguidas da numeração correspondente às escolas em que atuam. Uma das professoras atuava em duas escolas selecionadas.

${ }^{8}$ Importamos do cristianismo o termo "confissão" para representar aqui mecanismo de registro das conversas das professoras, por entendermos que se estabeleceu um ritual de confissões em que o que elas falavam era ao mesmo tempo de quem elas falavam, mas, de certa forma, aquela confissão deveria permanecer secreta. Isto é, segundo Foucault, fragmentos em "que aquele que fala é ao mesmo tempo aquele de quem se fala", e "não o papel eminente que lhe reserva o cristianismo" (Foucault, 2010, p. 2013).
} 
o que podemos no encontro com a infância? um convite a um olhar heterotópico

mecanismos de segurança são operacionalizados na escola. Assim, nesse recorte analítico, pretendeu-se atentar para algumas das possíveis dobras ${ }^{9}$ que a articulação das práticas da Educação Especial com a Educação Infantil analisadas produz na infância.

\title{
3. escola, deficiência e governo: o que pode a infância?
}

\begin{abstract}
Mas, antes de prosseguir, um alerta: o que segue não tem caráter nem de denúncia nem de lamentação; isso é assim simplesmente porque não pressuponho um ideal de educação escolarizada e de sociedade em relação ao qual a escola moderna teria se desviado ou o qual ela não tivesse (ainda) atingido. Isso não significa que não seja importante a busca de determinados ideais, seja para a escola, seja para a sociedade; significa, tão somente, que este texto se movimenta no campo da análise e da problematização. (Veiga-Neto, 2000, n/p,).
\end{abstract}

A partir das confissões, percebemos um cenário potente para provocar discussões outras, como tentativa de bagunçar um pouco o pensamento costumeiro e ordeiro que conduzia e produzia muitas daquelas professoras. Ao mesmo tempo, percebemos naquelas práticas, naqueles contextos e discursos, movimentos potentes de resistência que pensavam a infância a partir de outro lugar. Deparamonos com um mesmo nó que unia ao mesmo tempo as práticas "ideais" / utópicas e as práticas realizáveis.

Ao percebermos que essas práticas eram indissociáveis, não poderíamos empreender uma analítica que as confrontasse, colocando-as umas contra as outras. Buscamos, então, empreender uma analítica crítica e reflexiva, como possibilidade de convidar o pensamento a também problematizar as questões que se apresentaram naqueles discursos sobre a infância. Nossa ambição, parafraseando Jan Masschelein e Maarten Simons (2017, p. 29), “contudo, não é esboçar a escola ideal, mas uma tentativa de tornar explícito o que faz com que uma escola seja uma escola, e, consequentemente, diferente de outros ambientes de aprendizagem (ou

\footnotetext{
${ }^{9}$ Inspiradas em Deleuze (2005), compreendemos a noção de "dobras" como o pensamento sobre a produção de subjetividades. Expressa o pensamento que está no interior, do lado de dentro, mas que também é constituído pelo exterior, nas/pelas relações de poder e saber que produzem a interioridade.
} 
de socialização, ou iniciações)". Trata-se, então, de mostrar que a escola é também um lugar que produz "bons encontros (aqueles que aumentam a potência dos envolvidos no processo)" (Paraíso, 2010, p. 601).

Nesse sentido, dois caminhos analíticos mostraram-se igualmente potentes: um primeiro que nos conduziu a pensar e problematizar a produção da infância deficiente a partir das tramas discursivas que têm potencializado a produção da norma, de um ideal de desenvolvimento humano e de um ideal de sujeito acentuado na escola pelas práticas da Educação Especial; e um segundo que possibilitou pensar outras práticas possíveis, as realizáveis, que, desde dentro, deste mesmo lugar que produz a norma, produziram também a infância como heterotopia.

\section{1 a captura da infância: a naturalização das práticas de normalização}

As verdades produzidas nos cenários, imbricando as práticas da Educação Especial e da Educação Infantil, operam ações de subjetivação nas professoras. Práticas e discursos que se mostraram alinhados aos discursos dos saberes médicos e das pedagogias psicológicas, que se sustentam na estrutura moderna por produzirem e pensarem o desenvolvimento humano como resultado de um processo de evolução que, consequentemente, produz os modos de pensar a infância.

Segundo Márcia Lunardi-Lazzarin (2004), podemos pensar que a Educação Especial tem como matriz histórica a perspectiva do controle social, na medida em que vai se constituindo como campo do saber que se "preocupa com a educação dos sujeitos considerados deficientes" (Lunardi-Lazzarin, 2004, p. 17). Preocupação que estreita relações com a produção discursiva dos outros campos dos saberes, para inventar verdades e capturar os sujeitos que suas práticas produzem. Ambos os saberes, na nossa compreensão, emergem como mecanismo de controle para a manutenção da ordem escolar e social, com vistas a universalizar a produção de um sujeito e da infância.

Pensamos que "as crianças são constantemente produzidas pelos discursos que se enunciam sobre elas" (Bujes, 2002, p. 24). Mesmo que tenham algumas distinções ao nascer, biológicas, sociais, culturais, econômicas, etc., o "que faz com 
o que podemos no encontro com a infância? um convite a um olhar heterotópico

que tais distinções sejam significativas é o sentido que damos a elas" (Bujes, 2002, p. 24). Logo, não entendemos que os significados atribuídos à infância resultam de um processo de evolução, mas que "são resultados de um processo de construção social" e, por isso, "dependem de um conjunto de possibilidades que se conjugam em determinado momento da história, são organizados socialmente e sustentados por discursos nem sempre homogêneos e em perene transformação. (Bujes, 2002, p. 24-25).

Significados calcados no interior das relações de poder e saber que exprimem interesses específicos do Estado e da sociedade que, historicamente, implicam a produção de determinados regimes de verdade ${ }^{10}$ sobre os modos de ser e pensar a infância. Isso denota que os discursos e práticas engendrados historicamente, na Contemporaneidade, são atravessados pelo imperativo da normalidade e, na medida em que naturalizam as práticas de normalização e disciplinamento, produzem alguns dos significados atribuídos à infância por meio das ações da Educação Especial. Por vezes, estas práticas têm acentuado uma divisória entre normalidade e anormalidade como fundamento de boa parte das práticas empreendidas na Educação Infantil, a partir de um regime de verdade que veio se constituindo com e a partir da política de ampliação da obrigatoriedade de frequência.

Assim, as confissões expõem algumas práticas que a Educação Especial produz quando se articula à Educação Infantil para produzir verdades, enquanto campos do saber, e nos fazem perceber o desenvolvimento de ações que anulam a dimensão subjetiva das crianças em favor de ações que as normalizam, disciplinam e definem seu desenvolvimento. Práticas que colocam uns em comparação com os outros, potencializando a produção de uma infância normal e de uma infância deficiente.

Quanto mais cedo começar essa inserção, começar com esse estímulo, começar a ir para sala de aula, muito mais cedo vai sair o resultado lá na frente (E5-EE2);

\footnotetext{
${ }^{10}$ Regimes de verdade entendidos, a partir de Foucault, como os discursos, as narrativas, os saberes que orientam o que se pode dizer sobre determinado objeto, neste caso, sobre a infância; operam com caráter de verdade nas/pelas práticas, e, à medida que essas concepções são naturalizadas, um sentido "universal" de pensar sobre o objeto é fixado, como os saberes médicos, clínicos e pedagógicos.
} 
A estimulação precoce, quanto mais cedo a criança for estimulada (...), mais evolução ela vai ter (E10-EE9).

Visualizamos que as professoras confessam: "quanto mais cedo a inserção na escola, melhor". Palavras que expressam algo cada vez mais recorrente no discurso educacional contemporâneo: a inserção antecipada. A escola "confere uma prova de certificação de qualificação dos resultados de aprendizagens e das competências adquiridas" (Masschelein; Simons, 2017, p. 20) ao longo da vida dos sujeitos, ou tentam, ao menos, servir como garantia para que tenham aprendizagens ao longo das trajetórias escolares. Ou seja, antecipar a inserção na escola mostra-se como garantia de aprendizagem, de estímulo, de desenvolvimento, de evolução, de normalização e de prevenção do risco.

A Modernidade pôs em funcionamento a discursividade de que a escolarização só adquire sentido a partir da existência de um determinado tipo de ator, o corpo infantil (Mota, 2010), e dela vêm sendo produzidas justificativas para o alargamento do alcance da escola sobre a população. Tal fator colabora para que a frequência das crianças na escola seja inquestionável (Hattge, 2014). Disso emerge a necessidade de aproximar as crianças, conhecê-las e determinar lugares individuais para tornar possível, segundo Foucault (2014, p.144), “o controle de cada um e o trabalho coletivo simultâneo de todos".

A gente começa a fazer uma análise, fazemos um levantamento, uma análise do que está em atraso e/ou é só falta de estímulo, ou se é alguma questão do desenvolvimento. (Escola $2+$ Escola 5 - EE 2);

Eu faço todo um diagnóstico do aluno, faço uma caracterização desses alunos e vejo o que é principal para ele desenvolver. (Escola 8 - EE7).

Consequentemente, entendemos que aproximar as crianças da escola, antecipar para conhecer, para produzir saberes, contribui para que se definam e se determinem modos de ser mais adequados e produtivos para governar a sociedade. É importante ressaltar que, à medida que as crianças passam a supostamente ser compreendidas em suas especificidades e "essência", ao serem inseridas em um espaço e tempo escolar, se tornam objeto de intervenção do Estado e também do campo científico, servindo "de parâmetro para produzir a regulação e a 
o que podemos no encontro com a infância? um convite a um olhar heterotópico

normalização" (Bujes, 2002, p. 41) dos corpos e da população como uma verdade que vai conduzindo a todos.

No sentido de socialização, no sentido do conhecimento, no sentido acadêmico mesmo de aprendizagem, (...) ela já sai muito além de uma criança que só chega na pré-escola. (Escola $2+$ Escola 5 - EE 2).

A inserção na escola antes da obrigatoriedade tem sido compreendida como um benefício tanto para que a criança já se habitue ao ambiente escolar, às demandas e às rotinas estruturadas, quanto para o trabalho da professora na sala de aula, que percebe a importância de a criança estar disciplinada para manter a ordem, a organização, a normalidade e a condução das crianças no espaço escolar e na sociedade.

Tal percepção demonstra, por um lado, o assujeitamento das professoras à política de ampliação da obrigatoriedade de frequência, na medida em que reforça os discursos que dão condições de possibilidade para se pensar em uma antecipação e captura ainda mais cedo que aos quatro anos de idade. Por outro lado, mas não oposto, evidencia o caráter positivo que o controle e a previsibilidade sobre os processos de desenvolvimento das crianças e seus comportamentos produzem quando se aproxima a criança, o mais cedo possível, dessa rede de sujeição, disciplinamento, controle e regulação. Por isso,

A criança que já entra antes, é muito mais tranquilo ela se adaptar (E1+E3-EE1);

As crianças que já entram desde o início do berçário, por exemplo, se tem algum, qualquer atrasado, já lá no berçário se faz uma intervenção (E8-EE7).

Essas confissões levam-nos a pensar que a escola, enquanto espaço disciplinar, "fabrica" sujeitos, corpos infantis e modos de ser adestrados e obedientes (ou faz incidir práticas sobre os corpos que buscam esse adestramento) para torná-los alvos e agentes do governamento (Foucault, 2014). Isso porque, ao proporcionar-se a socialização com o outro, a internalização individual e ao mesmo tempo coletiva dos comportamentos e condutas considerados adequados é intensificada. Assim, na constituição de um controle do corpo individual e coletivo, 
percebemos a emergência do biopoder ${ }^{11}$ (Hattge, 2014, p. 94), que não exclui a técnica disciplinar, mas a integra na preservação dos discursos "científicos" que concebem um ideal de sujeito normal, naturalizando os processos de subjetivação e objetivação.

Portanto, quando a criança passa a ser alvo de observação constante ao entrar na escola, vai se constituindo uma rede de saber que dá visibilidade e possibilidades para se inventar um ideal de sujeito em que o desenvolvimento evolucionista é tido como única verdade.

Se foge um pouquinho das crianças, do que elas estão acostumadas, elas já pedem pra eu dar uma olhada. (Escola 9 - EE 8);

Quando a professora observa uma discrepância no desenvolvimento da linguagem, a agitação (...) que eu acho bem coerente, porque são indicadores fortes, (...) dependendo da idade da criança, claro. (Escola 7 - EE 6).

A naturalização da necessidade de produção de uma verdade sobre cada diferença, pouco a pouco, começa a determinar os níveis e gradientes dos comportamentos e aprendizagens que podem ou não ser aceitos no contexto de sala de aula, como também da sociedade. De toda forma, tudo que é observado e detectado pelas professoras passa a ser um procedimento necessário de classificação para identificar as crianças que são o risco para a desordem. São sinalizações que anunciam, como efeito, a produção da infância normal e da infância anormal.

Está todo mundo sentado, olhando TV, e ele não olha, fica andando ali pela sala. (ESCOLA 4 - EE 4);

Perto de outras crianças, ele tem esses atrasos. (ESCOLA $2+$ ESCOLA 5 - EE 2).

Pode-se pensar que é na escola, no espaço e tempo da Educação Infantil, que a infância ou o corpo infantil se torna alvo de vigilância e vai sendo moldado e conformado à norma instituída como ideal. É na/ pela comparação entre as crianças

\footnotetext{
${ }^{11}$ No curso "Segurança, Território, População" (1978), Foucault analisa as condições de possibilidade do aparecimento de uma nova tecnologia de poder - biopoder -, operada sobre a vida para a manutenção de sua segurança. Tal tecnologia de poder age por meio de mecanismos para promover o alcance de uma condição permanente de segurança (seguridade) para a população e para cada indivíduo que a constitui e encontra nos mecanismos jurídicos legais e nos mecanismos disciplinares (em uma relação de deslocamento e aperfeiçoamento) condições para sua emergência.
} 
o que podemos no encontro com a infância? um convite a um olhar heterotópico

que os comportamentos, as ações e os modos de agir vão consolidando, de uma vez por todas, as noções de desenvolvimento normal e anormal, ideal e indesejado, como uma grande verdade universal no cenário educacional, o que produzirá, por sua vez, uma verdade sobre os modos de ser da infância. Desse modo, percebemos a produção da infância deficiente pela vontade de saber evidenciando e localizando a escola como lugar privilegiado de gerenciamento dos riscos:

Vários relatos de pais que, quando eles fazem as avaliações desde pequenininhos, já encaminham para a escola quando suspeitam de alguma coisa (...) já encaminham para a escola. (Escola $1+$ Escola 3 - EE 1);

O próprio médico desse outro menininho que entrou agora (...) colocou ali para a mãe, ano passado, na entrevista: imediatamente matricular na escola, procurar a fono, a psicóloga. (Escola 4 - EE 4).

À medida que as práticas vão se articulando, o olhar direcionado da professora vai selecionando aquelas crianças cujo comportamento perturbam a ordem, buscando-se, por um lado, as possibilidades de identificar uma anormalidade a ser corrigida ou então minimamente regulada. Ao mesmo tempo, os significados atribuídos a esses corpos, quando identificados e localizados como anormais, produzem uma identidade deficiente. Isso principalmente porque na escola a criança passa a ser percebida como o "sujeito da falta", alojando em si a condição de impossibilidade, quase exclusivamente.

Tu chegando à escola, o teu olhar, ele vai ser sempre para aquela criança que disseram que tem algo faltando, sempre vai ser. Ou não se alfabetizou, ou não fala, sempre (...) (Escola 7 - EE 6).

Dessa forma, o diagnóstico, nesse cenário (muitas vezes descontextualizado da vida social, cultural, econômica, afetiva), servirá tanto como uma certificação clínica para o não investimento pedagógico (sobre alguns) quanto para a garantia dos direitos legais que a família e a escola precisam para justificar os encaminhamentos ao AEE e a necessidade de medicalização. Ambos os aspectos limitam as possibilidades múltiplas que o devir da infância convida a pensar, mas admitem que todos sejam alvos e agentes do exercício de governamento.

Com esse entendimento, percebemos que pouco se discute sobre os efeitos desses procedimentos e encaminhamentos. O importante é prevenir, conhecer, 
identificar, controlar e nomear - mesmo que a criança se torne refém "de uma incapacidade cientificamente atestada" (Lockmann, 2013, p. 139) para o resto de sua vida; mesmo que ela tenha em si a demarcação da anormalidade, seja objetivada e receba uma identidade deficiente. Com a identificação, com a identidade, com o diagnóstico, ela já não é um desconhecido, portanto, já não haverá mais riscos.

Nesse contexto, a escola passa a ser a instituição (disciplinar ${ }^{12}$ ) estratégica para colocar em funcionamento a governamentalidade ${ }^{13}$ biopolítica $^{14}$. A articulação das práticas da Educação Especial com a Educação Infantil e com saberes médicos, clínicos, terapêuticos e pedagógicos torna-se o mecanismo de controle eficaz que incide sobre o governo de si e dos outros, na medida em que forma uma rede que reforça as verdades produzidas para fixar e definir as identidades e os limites de/para um bom comportamento e desenvolvimento dentro (e fora) do contexto escolar.

Por isso, percebemos com Foucault (2014, p. 157) que na Educação Infantil “o poder se articula diretamente sobre o tempo; realiza o controle dele e garante sua utilização", de forma que cada um seja ajustado e disciplinado até que consiga se autogestar dentro daquele espaço e tempo, daquelas práticas, rotinas e atividades estruturadas, para alcançar o "ideal" de sujeito moderno. Em suma, é na escola que o tempo "evolutivo" (Foucault, 2014, p. 157) toma o sujeito como passível de condução e/ou correção permanentes.

\footnotetext{
12 Tecnologia de poder que surge entre o fim do século XVIII e o início do século XIX, tendo "por objeto os corpos e por objetivo sua normalização" (Castro, 2009, p. 110).

13 "Foucault utiliza o termo 'governamentalidade' para referir-se ao objeto de estudos das maneiras de governar. Encontramos, em consonância com os eixos da noção de governo [...] duas ideias de governamentalidade. [...] 1) O conjunto constituído pelas instituições, procedimentos, análises e reflexões, cálculos e táticas que permitem exercer essa forma de exercício do poder, que tem por objetivo principal, a população; por forma central, a economia política; e por instrumento técnico essencial, os dispositivos de segurança. 2) A tendência, a linha de força que, por um lado, no Ocidente, conduziu à preeminência desse tipo de poder que é o governo sobre todos os outros: a soberania, a disciplina, e que, por outro, permitiu o desenvolvimento de toda uma série de saberes. 3) O processo ou melhor, o resultado do processo, pelo qual o Estado de Justiça da Idade Média converteu-se, durante os séculos XV e XVI, no Estado administrativo e finalmente no Estado governamentalizado." (Castro, 2009, p. 190, grifo do autor).

14“ O termo 'biopolítica' designa a maneira pela qual o poder se encaminha para a transformação, entre o fim do século XVIII e o início do século XIX, a fim de governar não só os indivíduos por meio de uma série de procedimentos disciplinares, mas também o conjunto dos seres vivos que compõem a população: a biopolítica - por meio dos saberes locais - se ocupará, portanto, da gestão da saúde, da higiene, da alimentação, da sexualidade, da natalidade, etc., na medida em que tais gestões se tornaram apostas políticas." (Revel, 2011, p. 24).
} 
o que podemos no encontro com a infância? um convite a um olhar heterotópico

Diante disso, convidamos a pensar que, muitas vezes, localizamos (pelo nosso discurso, práticas, encaminhamentos) no outro a (im)possibilidade de um modo outro de ser infância, uma vez que o problema sempre está no outro que não se submete à norma instituída como verdade. Essa norma não é questionada ou posta sob suspeita, mas questionam-se a anormalidade e os modos de ser outros que não se sujeitam a ela. Por isso, compreendemos com Foucault (2016) que a norma, como utopia, consola as práticas e os sujeitos por endossar um lugar e um modo de ser sujeito e infância desejáveis e seguros. A anormalidade, os modos outros de ser, a multiplicidade de ser infância, é a heterotopia, que contesta toda condição que imprime um modo de ser universal, "porque impede de nomear isto e aquilo, porque fraciona os nomes comuns ou os emaranha" (Foucault, 2016, p. XIII). É nesse sentido que nos inquietamos, pensando a infância de modos outros.

\section{2 possibilidades outras de pensar a infância como heterotopia}

A infância, enquanto alteridade e novidade, possui um absoluto poder desestabilizador. Por ser um estranho e trazer em seu ser a possibilidade de renovação do mundo, a infância é a própria desestruturação do mundo adulto e organizado. (Danelon, 2015, p. 208).

O convite ao pensamento vai na direção de pensar de outro modo a educação e a infância, "que não é nada mais do que pensar de outro modo nossa relação com o outro, que não requer outra coisa além de arriscar-se a pensar de outra maneira a mesmidade" (Ferre, 2003, p.15). Isto significa pensar o outro como exterioridade, como diferença, como alteridade, e não o outro como interioridade ou representação criada/inventada na/pela linguagem, sempre reduzido ao mesmo. Visualizamos que a problemática do pensamento moderno está em questionar a anormalidade e os modos de ser que não se sujeitam à norma instituída, e não o contrário, a produção de uma norma universal, que perversamente classifica, segrega e exclui.

No entanto, ainda que esse pensamento nos conduza a produzir a classificação e uma identidade para os sujeitos e seus modos de ser, a desenvolver e aprender na/a partir da escola e localizar a infância em um lugar inexistente, irreal, que a reduz a conceitos inventados e utópicos, algumas confissões 
investigadas mostraram-nos que existem, nesse mesmo lugar, possibilidades de pensar a infância de outros modos.

Lugar outro que olha para a infância e permite seu devir, sua alteridade, sua transgressão, não estabelecendo e definindo, de antemão, respostas esperadas. Um olhar que chamaremos de heterotopia (Foucault, 2015). E é deste "lugar outro" que buscamos aqui convidar a pensar de modos outros a infância. Diante disso, trazemos as confissões das professoras, que nos permitem perceber um olhar atento para a dimensão subjetiva das crianças e da singularidade de sua infância, o que tem deixado suspender o modo disciplinar e normalizador de pensar as infâncias.

Isso dá lugar a modos de pensar que apresentam uma sensibilização para o devir da infância e que se mostram como uma forma de resistir às demandas sociais que a escola incorpora nas suas práticas e discursos, em cada pequeno momento em que "impedem de nomear isto e aquilo", evidenciando que são possíveis um fazer e um pensar diferentes, a partir de uma exterioridade que promove outro pensamento. Trata-se de um olhar que não abandona as práticas disciplinares e normalizadoras aplicadas aos corpos, mas que, em alguns momentos, imbricadamente, atenta para a dimensão singular de cada infância, sem tentar representá-la em alguém ou em algum lugar ou com alguma nova identidade inventada. É um olhar que possibilita modos outros de ser/viver/estar infância, localizada entre a escola idealizada, utópica, e a escola possível, realizável, que propicia o devir da infância não capturada e da infância como heterotopia.

Antecipar para conhecer pela vontade de saber e pela vontade de verdade pode ser também uma chance de aproximar-se desse outro, do "estranho" que não conheço, mas que está aí e pode ser muitas coisas além do que meu discurso pode capturar. Ainda que alinhadas às normativas legais que estruturam as ações e práticas da Educação Especial, as confissões das professoras também dão atenção à infância outra que está ali presente, sem proibir que esse outro seja outro, sem a exigência de uma representação que o caracterize e/ou o relacione com alguma identidade já inventada. Elas confessaram que "têm crianças que estão deficientes, não 
o que podemos no encontro com a infância? um convite a um olhar heterotópico

são deficientes" (E3-EE3) ${ }^{15}$. O que torna relevante esse modo de pensar a infância é considerar que a diferença aqui é sua singularidade (Paraíso, 2010, p. 589). Então, convidar a voltar a olhar bem a infância que estamos produzindo é uma possibilidade de resistir às estratégias de governamento e estabelecer linhas de fuga.

Isso não para negar os rituais e invenções pedagógicos de ordenamentos, esquadrinhamento do tempo, sequenciações e estruturações: a hora do brincar, do conto, do soninho, da higiene, do lanche, de falar, de sentar, de correr, de interagir, da atividade, etc. É para colocá-los sob suspeita, para desconstruir a naturalização feita sobre o desenvolvimento normal e o anormal e, então, possibilitar pensar um tempo do outro que nos seja "irreconhecível, indefinível, inominável, ingovernável" (Skliar, 2003, p. 38). Um tempo mais flexível, menos definidor e determinador, menos linear e domesticador, mais variável, mais inventivo, um tempo de multiplicidades.

Percebemos e defendemos que a infância, assim como o tempo, carrega consigo a intempestividade que desobedece, muitas vezes, às invenções capturadas pela linearidade e cronologia do desenvolvimento humano da modernidade. Talvez por isso, estabelecer linhas de fuga no pensamento oportunize, na Educação Infantil, perceber que o "recém-chegado", o "estranho", o desconhecido, "tem o direito de ser estranho o quanto ele quiser" (Escola 3 - EE 3). Dispor-se a um olhar mais atento, em meio a um espaço de produção de identidades normais e anormais, favorece pensar o que estamos fazendo na Educação Infantil. Que infância é essa que estamos produzindo?

Além disso, esse olhar mais atento, deste mesmo espaço que produz a norma, mostra que existe um tempo mais flexível que tem sido considerado para aproximar e aconchegar o "estranho" no mundo ordeiro, domesticado, disciplinador, normalizador e rotineiro da escola. Percebemos que cada corpo e cada comportamento, ainda que avaliados e observados na articulação das práticas da Educação Especial com a Educação Infantil, têm sido localizados em “outro lugar". Está em um "entre lugar" que "rompe com a semelhança como processo e com a

\footnotetext{
${ }^{15}$ Nesta analítica, alguns fragmentos das confissões das professoras serão incorporados ao texto, recebendo destaque em itálico.
} 
identidade como princípio" (Paraíso, 2010, p. 289), que diferencia o processo de adaptação a esse espaço e o reconhecimento de si, e prioriza as singularidades, ou o diferenciar-se em si.

É um entre lugar que considera a singularidade da criança que "não está acostumada com a rotina" (Escola 3 - EE 3) ou que "precisa de uma atenção individual", sem que isso determine encaminhamentos ou produza uma identidade deficiente.

Ela não está acostumada com rotina, ela tem que aprender a ir ao banheiro, que tem aquela ordem para lavar as mãos, para sentar, para fazer o lanche, o "eu mesmo me sirvo". (Escola 3 - EE 3);

Ele precisa de uma atenção individual, e isso não caracteriza ele ser especificamente o público da Educação Especial ou até mesmo precisar de encaminhamento para o neuro. (Escola 7 EE 6).

Um entre lugar, desconhecido, variável, imprevisível, que desestabiliza muitas das certezas sobre o desenvolvimento humano, mas que dá condições para suspendê-las, sem expor ou negar as diferenças, sem as representar em algum lugar, nem as nomear com algum conceito que as defina ou que apague a própria diferença nos sujeitos, tomando-a como sinônimo de deficiência. Nesse entre lugar, não há como saber e controlar como e o que alguém aprende(rá) e desenvolve(rá); também não podemos, de antemão, determinar quem são(serão) os sujeitos e caracterizá-los ou definir suas (im)possibilidades. As singularidades estão perceptíveis e são consideradas em instantes (por algumas professoras) entre aquilo que acontece na escola estruturalmente e o que é possível fazer fora das margens ordeiras que a capturam.

Mas quem é esse desconhecido? Quem é esse estranho? Como dizê-lo sem o nomear? Como reconhecê-lo sem lhe produzir uma nova/outra identidade?

Mas aí, eu tenho que ver o que é um estranho para elas: é uma criança que não parou de chorar, que continua chorando, é uma criança apática (...) Às vezes, essa criança que "falo com ela, não me ouve" é porque, realmente, a escola é um mundo totalmente diferente. Ela saiu daquele ninho, ela não está acostumada a pegar a mochila, tirar uma agenda da mochila, ir lá na professora, guardar a agenda (...) (Escola 3 - EE 3).

Entendemos que (re)pensar o que pensamos sobre as crianças contribua para que consigamos desnaturalizar o olhar que busca atribuir sentidos e nomes para 
o que podemos no encontro com a infância? um convite a um olhar heterotópico

cada gesto, cada comportamento que se diferencia de uma condição de normalidade inventada. Isso porque o "estranho", talvez, não precise ser capturado e nomeado. Assim, a Educação Especial, ao perceber como a professora da sala de aula está compreendendo e produzindo essa criança, poderá provocá-la a também relativizar e repensar determinados comportamentos, para entender que ali, naquela criança, naquela infância, existe uma diferença que não precisa ser individualizada e nomeada.

As confissões mostram que é necessário considerar vários elementos, indo além dos muros da escola, para poder entender esses modos de ser, de estar e de comportar-se que fogem das margens da infância considerada normal. “Tu olhas para o contexto familiar. Quando tu já vês uma mãe, uma vó, tu já pensas que aquele contexto familiar é infantilizador" (E3-EE3). "Às vezes, também, essa criança pode estar assim evidenciando determinado comportamento por causa de uma situação que está vivendo em casa ou da maneira que a dinâmica familiar se organiza" (Escola 7 - EE 6).

Todo aquele contexto, afinal de contas, é um novo mundo para essa criança. É um novo mundo "estranho" também, desconhecido. As novas rotinas e estruturas também lhe são estranhas. Talvez, o foco possa ser colocado em todos, e não em uma criança em particular. "E isso não significa que as questões e necessidades individuais não sejam levadas em conta ou sejam negligenciadas, porém significa que elas não podem ser o ponto de partida para o professor" (Masschelein; Simons, 2017, p. 83) determinar ou produzir uma nova identidade para essa criança.

Percebemos, então, que algumas professoras visualizam, nas dobras que a articulação das práticas produz, uma possibilidade, uma linha de fuga para tornar possível o deslocamento de pensar a infância além da filosofia da representação. Em vários momentos, as professoras ocuparam-se de pensar de outros modos a escola, a infância e suas relações, mostrando que é possível observar a multiplicidade das singularidades de dentro do espaço mesmo, resistindo às demandas normativas.

Algumas professoras conseguiram encontrar linhas de fuga em meio ao campo que pensa a diferença em sua relação com uma identidade inventada, observando e percebendo o outro com mais cuidado, com mais atenção, e entendendo que não é necessário encaminhar as crianças para a rede de 
atendimentos que vai auxiliar na captura e produção de um diagnóstico ou na identificação de uma anormalidade pelo fato de que não se ajustam às normas inventadas no tempo cronológico determinado ideal. Encontram linhas de fuga quando compreendem que cada corpo e comportamentos agem de maneira única e podem estabelecer relações e processos de aprendizagens muito diferentes dos naturalizados por nós, mostrando-nos que as crianças não precisam "estar sentad[as] o tempo todo" para aprender a ou b, não precisam seguir uma sequência "lógica" determinada a priori para aprender c ou $\mathrm{d}$.

A produção de identidades dentro da escola moderna e as possibilidades de transgressão não são facilmente separadas e percebidas. Porém, de certa forma, essa criança que está ali, esse "estranho", esse desconhecido, está ali estabelecendo relações e se desenvolvendo de um modo outro, singular, para mostrar que tem suas subjetividades e que, ainda assim, é possível resistir a essa classificação e identificação, aprender e desenvolver-se.

O aluno que está chegando (...) mesmo o aluno que está lá no pré-B, ele não é mais o aluno que terminou o ano. Ele teve férias, cresceu ou fez aniversário, amadureceu. Não espera ele voltar para a escola do mesmo jeito que ele entrou no ano passado. (Escola 3 - EE 3).

Ainda que as professoras não pensem esse deslocamento pela perspectiva da filosofia da diferença, porque seus processos formativos estão estruturados para a escola moderna, a partir de uma filosofia da representação, de um ideal de sujeito a ser alcançado, muitas delas têm percebido que há várias possibilidades de ser e estar que escapam dessas demandas ideais projetadas. Há uma multiplicidade que não está sendo capturada, que escapa, que encontra fissuras nas malhas do poder e desafia os saberes. Há singularidades que não se enquadram na estrutura moderna de desenvolvimento, mas que, mesmo assim, estão sendo consideradas, percebidas e respeitadas por algumas professoras. Essa multiplicidade está no micro, quase invisível, mas está ali, em cada "estranho" que não se sujeita à norma ou que não é objetivado com uma identidade inventada. Está ali quando o olhar atenta para a singularidade. 
o que podemos no encontro com a infância? um convite a um olhar heterotópico

para continuarmos pensando...

Na busca por compreender que infância é essa que vinha sendo produzida pela Educação Especial, percebemos que os discursos produzidos sobre a infância se estabeleciam a partir de uma rede de saberes e poderes que utilizavam as verdades já produzidas e estabelecidas como estratégia para o assujeitamento dos sujeitos e das práticas. Verdades que determinaram modos de ser e de comportarse na escola que obedecem às regras historicamente constituídas pelas diferentes áreas do saber, principalmente, pela psicologia do desenvolvimento.

Esses saberes foram se estabelecendo nos processos (des)contínuos históricos, políticos e sociais, propiciando algumas condições de proveniência e emergência para a naturalização da política de ampliação da obrigatoriedade de frequência enquanto estratégia de governamentalidade biopolítica e para a manutenção do ideal normal de sujeito, de desenvolvimento e de aprendizagem.

A Educação Especial, nessa lógica, com e mediante suas práticas, muitas vezes veio/vem reforçando esse ideal de sujeito, pois tem operacionalizado mecanismos de correção permanentes, na tentativa de homogeneizar as infâncias, sem pensar e problematizar os efeitos dessas práticas na constituição dos sujeitos. Ainda que doloroso reconhecer a Educação Especial como meio pelo qual as condições de possibilidade de produzir a infância deficiente são efetivadas na escola, provocamo-nos a pensar que as confissões dessas práticas podem servir para que reflitamos sobre que infância é essa que estamos produzindo, ou ao menos para tornar possíveis modos outros de pensar a infância que chega.

Percebemos que há um interesse outro pelas infâncias, atravessado por um movimento de resistência também das professoras. Contracondutas que se estabelecem para distanciar as abordagens de desenvolvimento humano como um produto ou resultado de um processo evolutivo, pois muitas têm percebido alguns dos efeitos desse modo de pensar na produção das subjetividades das crianças. Algumas confessaram que pensar a infância e as práticas desse modo outro, mais flexível e desestruturado dessas rotinas e exigências curriculares, seja (mais) possível, talvez, na Educação Infantil, porque nesse espaço é "permitido" um deslocamento maior da Educadora Especial entre as salas de aulas, entre as 
atividades, entre os planejamentos, entre as rotinas e projetos propostos pela professora na sala, do que em outras etapas de ensino.

A interlocução entre Educação Especial e Educação Infantil tem se mostrado acontecer de maneira mais "tranquila", visualizada como uma prática possível para repensar os modos de ser/estar na escola. Mas isso não significa que outras práticas que aconteçam em outros espaços, com outras interlocuções, de outros modos, não possam levar a repensar os modos de ser e estar na escola. Na sala de aula, "tu olhas pra vários, entendes? E daí, tu podes relativizar essa falta e pode falar isso pra elas. Isso te dá argumentos" (E7-EE6) para pensar e problematizar os modos de produção da infância, na articulação das práticas da Educação Especial com a Educação Infantil.

Com a articulação das práticas, a escola deixa de ser pensada exclusivamente como uma função da sociedade de governamentalidade, "embora também o seja”, e pode ser vista como "um 'espaço livre', ainda não completamente determinado pelas demandas da sociedade" (Biesta, 2018, p. 28).

É nessa relação indissociável entre utopia e heterotopia que percebemos a produção da infância acontecer. A produção de uma infância deficiente entre as práticas que buscam exclusivamente considerar a representação que inventa e projeta uma identidade para atender às demandas sociais, mas também uma infância outra, com práticas mais suspensas e atentas, que tomam a infância como heterotopia. Práticas em que se pensa de modos outros, se considera o que é real e singular, aquilo que está ali na criança e que não se sujeita à produção discursiva normalizadora e disciplinar. É nesse “entre lugar" que se produz o que é possível, que as linhas de fugas são estabelecidas e nos oferecem a possibilidade de resistir às infâncias que estamos produzindo sem pensar nos seus efeitos, para pensá-la de modos outros.

Esse olhar permite perceber e afirmar existir a possibilidade de pensar uma infância como heterotopia. Um olhar imbricado nas práticas de normalização, mas que encontra linhas de fuga, brechas e outros caminhos para ressignificar as verdades produzidas sobre o ideal de infância. Esse olhar, essas práticas, essas possibilidades outras, mostraram-nos que é possível aproximar-se da infância sem 
o que podemos no encontro com a infância? um convite a um olhar heterotópico

buscar ali uma representação que a caracterize e/ou a relacione com alguma identidade já inventada.

Pudemos perceber que (algumas) professoras da Educação Especial, das dobras que a articulação das práticas com a Educação Infantil produziu, conseguem pensar modos outros de ser infância na escola, indo além da filosofia da representação. Ainda que, na sua formação pedagógica e na escola (moderna), não exista lugar para a diferença fora da representação, as microrresistências e contracondutas diárias estabelecidas para pensar uma infância outra permitem-nos dizer que sim, é possível resistir e provocar heterotopias. Porque a resistência "é a criação de possíveis" dentro da escola e, por isso, ela é também "força agenciadora que transforma e funda outras e novas relações" que podem ser estabelecidas nas pequenas brechas e ações cotidianamente (Paraíso, 2016, p. 408).

É o potencial de resistir que produz modos outros de pensar a infância na escola, nas práticas, na sociedade - nem melhores, nem piores, apenas outros, que possibilitam não apagar seu devir, mas apreciar sua multiplicidade de ser. Resistência que cria os momentos possíveis dentro da escola e leva a pensar a infância como heterotopia. Por isso, o convite ao pensamento permanece: o que podemos no encontro com a(s) infância(s)?

\section{referências}

Biesta, Gert. O dever de resistir: sobre escolas, professoras e sociedade. Revista Educação. Porto Alegre. Quadrimestral. v. 41, n. 1. p. 21-29, jan-abr. 2018

Brasil. Lei 12.796, de 4 de abril de 2013. Altera a Lei no 9.394, de 20 de dezembro de 1996, que estabelece as diretrizes e bases da educação nacional, para dispor sobre a formação dos profissionais da educação e dá outras providências.

Borges, Letícia de Lima. Modos outros de pensar a infância: um convite ao pensamento a partir da Educação Especial. 2019. 170 f. Dissertação (Mestrado em Educação). Universidade Federal de Santa Maria, Santa Maria, RS.

Bujes, Maria Isabel Edelweiss. Infância e Maquinarias. Rio de Janeiro: DP\&A, 2002.

Bujes, Maria Isabel Edelweiss. Descaminhos. In: Costa, Marisa Vorraber (org.) Caminhos investigativos II: outros modos de pensar e fazer pesquisa em educação. 2. ed. Rio de Janeiro: Lamparina Editora, 2007.

Castro, Edgardo. Vocabulário de Foucault - Um percurso pelos seus temas, conceitos e autores. Tradução Ingrid Müller Xavier. Revisão técnica Alfredo Veiga-Neto e Walter Omar Kohan. Belo Horizonte: Autêntica Editora, 2009.

Deleuze, Gilles. Foucault. Tradução Claudia Sant' Anna Martins; revisão de tradução Renato Ribeiro. São Paulo: Brasiliense, 2005. 
Danelon, Márcio. A infância capturada: escola, governo e disciplina. In: Resende, Haroldo. (Org). Michel Foucault: o governo da infância. Belo Horizonte: Autêntica Editora, 2015. cap. 12, p. 217-258.

Fischer, Rosa Maria Bueno. Trabalhar com Foucault: arqueologia de uma paixão. Belo Horizonte: Autêntica Editora, 2012.

Foucault, Michel. Os anormais: curso no Collège de France (1974-1975). Tradução Eduardo Brandão. São Paulo: Editora WMF Martins Fontes, 2010.

Foucault, Michel. A ordem do discurso: aula inaugural no Collège de France, pronunciada em 2 de dezembro de 1970. Tradução: Laura Fraga de Almeida Sampaio. 23. ed.- São Paulo: Edições Loyola, 2013. (Leituras Filosóficas).

Foucault, Michel. O corpo utópico, as heterotopias. Tradução: Salma Tannus Muchail. $1^{\mathrm{a}}$ ed. N-1 Edições, 2013.

Foucault, Michel. Vigiar e Punir. Tradução: Luiz Felipe Baeta Neves. 8 ed. Rio de Janeiro: Forense Universitária, 2014

Foucault, Michel. As palavras e as coisas: uma arqueologia das ciências humanas. Tradução: Salma Tannus Muchail. 10. Ed. São Paulo: Martins Fontes - selo Martins, 2016.

Foucault, Michel. Outros espaços. In: Barro Da Motta, Manoel (Org.). Estética: literatura e pintura, música e cinema. Ditos e Escritos III. Tradução: Inês Autran Dourado Barbosa. 4 ed. Rio de Janeiro: Forense Universitária, 2015.

Ferre, Nuria Pérez de Lara. Pensar muito além do que é dado, pensar a mesmidade a partir do outro que está em mim. In: Skliar. Carlos. Pedagogia (improvável) da diferença: e se o outro não estivesse aí? Tradução: Giane Lessa. Rio de Janeiro: DP\&A, 2003.

Gallo, Silvio. Pensar a escola com Foucault: além da sombra e da vigilância. In: Carvalho, Alexandre Filordi de.; Gallo. Silvio (org.). Repensar a educação. São Paulo: Editora Livraria da Física, 2015. p. 427-449.

Hattge, Morgana Domênica. Performatividade e inclusão no movimento todos pela educação. 2014. 182f. Tese (doutorado). Universidade do Vale do Rio dos Sinos.

Kohan, Walter Omar. Infância. Entre educação e filosofia. 1. ed., 1. reimp. - Belo Horizonte: Autêntica, 2005.

Lunardi, Márcia Lise. Educação Especial: institucionalização de uma racionalidade específica. In: A invenção da surdez: cultura, alteridade, identidade e diferença no campo da educação. Thoma, Adriana da Silva (Org.); Lopes, Maura Corsini (Org.). Santa Cruz do Sul: EDUNISC, 2004. 236p.

Lunardi-Lazzarin, Márcia Lise.; Menezes, Eliana Pereira. Pesquisas em Educação Especial: investigações a partir dos estudos pós-críticos em educação. In: Costas, Fabiane Adela Tonetto.; Pavão, Sílvia Maria de Oliveira. (Orgs.). Pesquisa em Educação Especial: referências, percursos e abordagens. 1. ed. Curitiba, Apris, 2015. p. 199-214.

Lockmann, Kamila. Medicina e inclusão escolar: estratégias biopolíticas de gerenciamento do risco. In.: Fabris, Eli T. Henn; Klein, Rejane Ramos (Orgs.) Inclusão e biopolítica. Belo Horizonte: Autêntica Editora, 2013.

Masschelein, Jan; Simons, Maarten. Em defesa da escola: uma questão política. Tradução Cristina Antunes. 2a ed.; 2. reimp. Belo Horizonte: Autêntica Editora, 2017.

Mota, Maria Renata Alonso. As crianças de seis anos no ensino fundamental de nove anos e o governamento da infância. 2010. 175f. Tese (Doutorado em Educação). Universidade Federal do Rio Grande do Sul.

Paraíso, Marlucy. Diferença no currículo. Cadernos de Pesquisa, v. 40, n. 140, p. 587-604, maio/ago., 2010.

Paraíso, Marlucy. A Ciranda do Currículo com gênero, poder e resistência. Currículo sem Fronteiras. v. 16, n. 3, p. 388-415, set./dez., 2016.

Resende, Haroldo. (Org). Michel Foucault: o governo da infância. Belo Horizonte: Autêntica Editora, 2015. 
o que podemos no encontro com a infância? um convite a um olhar heterotópico

Revel, Judith. Dicionário Foucault. Tradução de Anderson Alexandre da Silva; revisão técnica Michel Jean Vicent. Rio de Janeiro: Forense Universitária, 2011.

Skliar, Carlos. Desobedecer a linguagem: educar. Tradução Giane Lessa. $1^{a}$. ed. Belo Horizonte: Autêntica Editora, 2014.

Veiga-Neto, Alfredo. Espaços, tempos e disciplinas: as crianças ainda devem ir à escola? In: Alves-Mazzotti, Alda et al. Linguagens, espaços e tempos no ensinar e aprender. Rio de Janeiro: DP\&A, 2000a. p. 9-20.

recebido em: 06.10 .2021

aprovado em: 15.12 .2021 